\title{
Determination of melamine in milk and dairy products by high performance liquid chromatography
}

\author{
A. Filazi, ${ }^{1}$ U. T. Sireli, † H. Ekici, $\neq$ H. Y. Can,§ and A. Karagoz\# \\ ${ }^{*}$ Department of Pharmacology and Toxicology, and \\ †Department of Food Hygiene and Technology, Ankara University, Faculty of Veterinary Medicine, Ankara, Turkey 06110 \\ fDepartment of Pharmacology and Toxicology, Kirikkale University, Faculty of Veterinary Medicine, Kirikkale, Turkey 71451 \\ $\S$ Department of Food Hygiene and Technology, Faculty of Veterinary Medicine, Mustafa Kemal University, Hatay, Turkey 31040 \\ \#Molecular Microbiology Research and Application Laboratory, Refik Saydam National Hygiene Center, Ankara, Turkey 06100
}

\section{ABSTRACT}

A simple, precise, accurate, and validated reversephase HPLC method was developed for the determination of melamine in milk (pasteurized and UHT milk) and dairy products (powdered infant formula, fruit yogurt, soft cheese, and milk powder). Following extraction with acetonitrile:water (50:50, vol/vol), samples were purified by filter $(0.45 \mu \mathrm{m})$, separated on a Nucleosil C8 column $(4.6 \mathrm{~mm} \times 250 \mathrm{~mm}, 3 \mu \mathrm{m})$ with acetonitrile: $10 \mathrm{mmol} / \mathrm{L}$ sodium L-octane sulfonate (pH 3.1; 15:85, vol/vol) as mobile phase at a flow rate of $1 \mathrm{~mL} / \mathrm{min}$, and determined by a photodiode array detector. A linear calibration curve was obtained in the concentration range from 0.05 to $5 \mathrm{mg} / \mathrm{kg}$. Milk and dairy products were fortified with melamine at 4 levels producing average recovery yields of 95 to $109 \%$. The limits of detection and quantification of melamine were 35 to 110 and 105 to $340 \mu \mathrm{g} / \mathrm{kg}$, respectively. The method was then used to analyze 300 samples of milk and dairy products purchased from major retailers in Turkey. Melamine was not found in infant formulas and pasteurized UHT milk, whereas $2 \%$ of cheese, $8 \%$ of milk powder, and $44 \%$ of yogurt samples contained melamine at the 121, $694 \pm 146$, and $294 \pm 98 \mu \mathrm{g} /$ $\mathrm{kg}$ levels, respectively. These findings were below the limits set by the Codex Alimentarius Commission and European Union legislation. This is the first study to confirm the existence of melamine in milk and dairy products in Turkey. Consumption of foods containing these low levels of melamine does not constitute a health risk for consumers.

Key words: melamine, dairy product, HPLC, milk

Received September 12, 2011.

Accepted October 13, 2011.

${ }^{1}$ Corresponding author: filazi@veterinary.ankara.edu.tr

\section{INTRODUCTION}

Melamine (2,4,6-triamino-1,3,5-triazine, $\left.\mathrm{C}_{3} \mathrm{H}_{6} \mathrm{~N}_{6}\right)$ is an organic base chemical most commonly found in the form of white crystals rich in nitrogen. It is produced in large amounts primarily for use in the synthesis of melamine formaldehyde resins for the manufacture of laminates, plastics, coatings, commercial filters, glues or adhesives, and dishware and kitchenware (WHO, 2009).

Aside from common commercial uses, melamine became a topic of discussion in 2007 when veterinary scientists determined that pet food contamination of melamine was the cause of hundreds of pet deaths (Tyan et al., 2009). Melamine was implicated in a major pet food recall throughout the United States and Canada. Certain imported cereal-based pet food ingredients (e.g., wheat flour, wheat gluten, corn flour, and rice protein concentrate were deliberately adulterated with melamine to boost their total nitrogen content (melamine contains $66.6 \% \mathrm{~N}$ by weight; Ehling et al., 2007). Ingestion of melamine may lead to kidney stones, renal failure, and other health problems (Chen and Yan, 2009). In 2008, high concentrations of melamine were reported in contaminated Chinese infant formula. The World Health Organization (WHO) reviewed the 2008 melamine contamination event of China. More than 51,900 infants and young children in China were hospitalized for urinary problems, possible renal tube blockages, and possible kidney stones related to the consumption of melamine-contaminated infant formula and related dairy products. Six deaths among infants were confirmed in China (Xu et al., 2009).

Soon after, melamine was found in liquid milk and yogurts, frozen desserts, powdered milk, cereal products, confectionaries, cakes and biscuits, protein powders, and some processed foodstuffs. Subsequently, various nondairy products originating from China were found to be contaminated with melamine. These products included ammonium bicarbonate, animal feed and animal 
Table 1. Analytical conditions for HPLC

\begin{tabular}{ll}
\hline Instrument & Shimadzu LC-20A system (Shimadzu, Tokyo, Japan) \\
\hline Column & Nucleosil $120-3 \mathrm{C} 8$ column; $4.6 \mathrm{~mm}$ (internal diameter) $\times 250 \mathrm{~mm}$ \\
& (length), $3 \mu \mathrm{m}$ (Macherey-Nagel, Düren, Germany) \\
Mobile phase & $\mathrm{A}=10 \mathrm{mmol} / \mathrm{L}$ sodium citrate buffer containing $10 \mathrm{mmol} / \mathrm{L}$ sodium \\
& L-octane sulfonate $(\mathrm{pH} 3.1) ; \mathrm{B}=$ acetonitrile; A $\mathrm{B}=85 / 15$ \\
Flow rate & $1.0 \mathrm{~mL} / \mathrm{min}$ \\
Column temperature & $40^{\circ} \mathrm{C}$ \\
Detector & SPD-M20A photodiode array UV-VIS spectrophotometric detector (Shimadzu, Tokyo, Japan) \\
Detection wavelength & $240 \mathrm{~nm}$ \\
\hline
\end{tabular}

feed ingredients, dried whole egg, fresh hen eggs, and nondairy creamer (Gossner et al., 2009).

Melamine is not a natural product and is not approved for direct addition to food or feed; however, it is approved for use as part of certain food-contact substances (Tyan et al., 2009). To protect public health and food safety, many countries have established maximum residue limits (MRL) for melamine in various products. For example, the European Union (EU) set the MRL of melamine in dairy products and high-protein foods at $2.5 \mathrm{mg} / \mathrm{kg}$, whereas the US FDA set the MRL of melamine in milk and dairy products and milk foods as $0.25 \mathrm{mg} / \mathrm{kg}$, and stressed that infant formula sold to US consumers must be completely free of melamine. On April 22, 2010, the Ministry of Health of China published new dairy safety standards and emphasized that food should not be tainted with melamine. In other words, any act of adding melamine to dairy products artificially is illegal, even if the amount is much lower than the MRL (Guo et al., 2011).

Intensive controls on melamine by national safety authorities, importers, producers, and other parties of the food industry worldwide are being conducted to protect human health. Therefore, there is an increasing need to perform melamine testing (Chen and Yan, 2009).

Several detection methods for melamine have been developed, such as GC, liquid chromatography, immunoassay, GC-MS, and liquid chromatography-MS (Wu et al., 2009). Current methods range from sensitive liquid chromatographic-tandem mass spectrometric techniques to less sensitive immunoselective assays such as ELISA. Difficulties in analysis may include contamination, matrix effects, and analyte instability. The effect of these difficulties generally depends on the

Table 2. Recovery, LOD, LOQ, and RSD for the method validation of melamine in milk and dairy products ${ }^{1}$

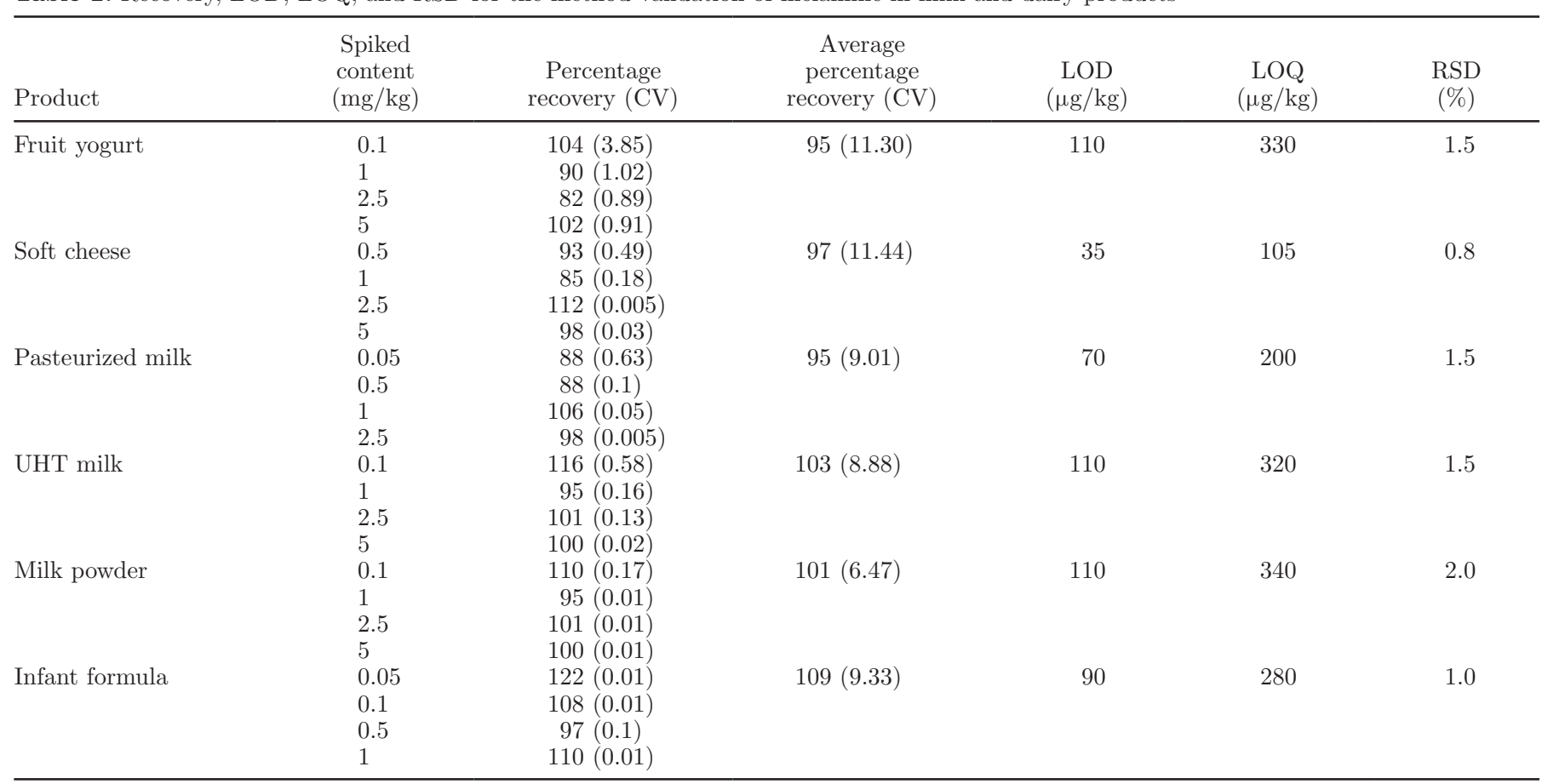

${ }^{1} \mathrm{LOD}=$ limit of detection; LOQ $=$ limit of quantification; $\mathrm{RSD}=$ relative standard deviation. 
A)

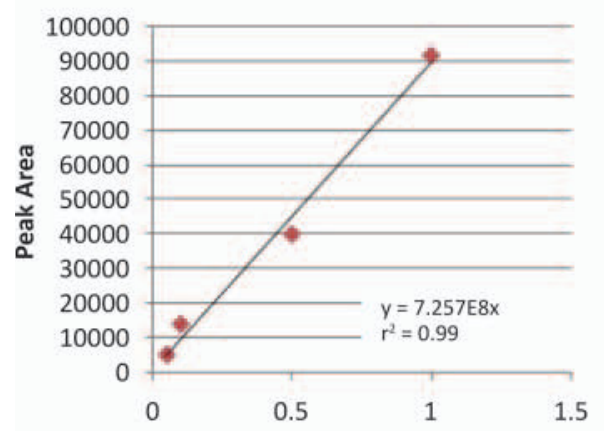

D)

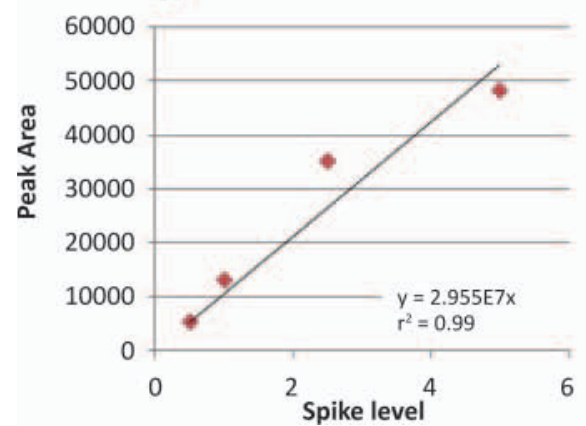

B)

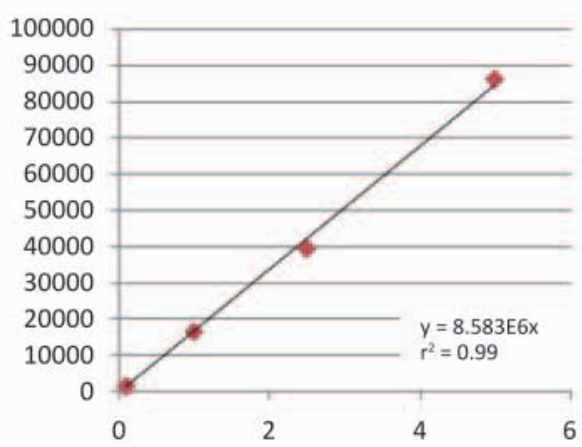

E)

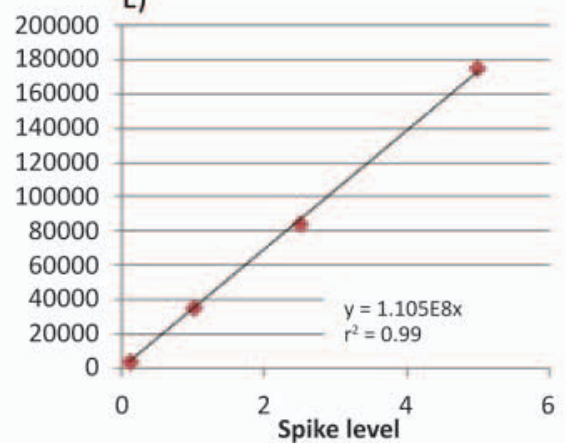

C)

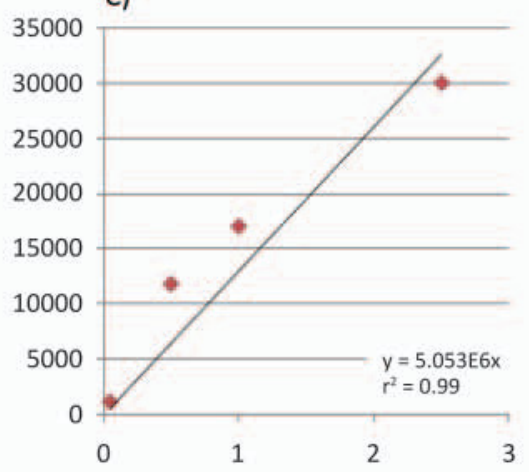

F)

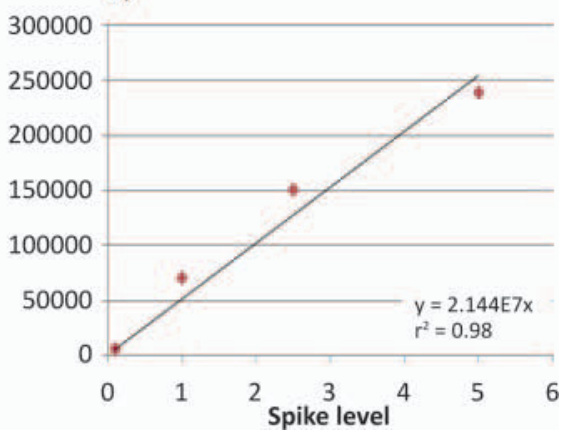

Figure 1. Calibration curves for melamine. Data obtained from the analysis of (A) infant formula, (B) yogurt, (C) pasteurized milk, (D) cheese, (E) milk powder, and (F) UHT milk fortified from 0.05 to $5 \mu \mathrm{g} / \mathrm{g}$ and then taken through the extraction procedure. Color version available in the online PDF.

method used, the food matrices involved, and the analyte examined (Tittlemier, 2010).

The present study proposes a simple, sensitive, and economical method for the analysis of melamine by reversed-phase HPLC in milk and dairy products and a routine monitoring program. The method was then used to analyze 300 samples of dairy milk purchased from major retailers in Turkey.

\section{MATERIALS AND METHODS}

\section{Chemicals, Reagents, and Equipment}

All reagents and solvents were analytical grade unless otherwise specified. Melamine (99\% purity) was purchased from Sigma-Aldrich (St. Louis, MO). Acetonitrile was HPLC grade and purchased from Merck (Darmstadt, Germany). Ultra-pure water was obtained from a Millipore system (Millipore, Molfheim, France). Disposable syringe filters (Chromafil Xtra PVDF-45/25 pore size $0.45 \mu \mathrm{m}$, membrane diameter of $25 \mathrm{~mm}$ ) were purchased from Macherey-Nagel (Düren, Germany). An ultrasonic bath (Bandelin Sonorex, Berlin, Germany), centrifuge (Beckman Coulter, Krefeld, Germany), and HPLC (Shimadzu, Tokyo, Japan) were used in sample treatment. The HPLC analytical conditions are given in Table 1.

\section{Preparation of Standards}

A stock standard solution of melamine was prepared at concentration of $10 \mu \mathrm{g} / \mathrm{mL}$ in water, stored in a refrigerator at $4^{\circ} \mathrm{C}$ in the dark, and used to prepare working standard solutions by appropriate dilution with the mobile phase. Each standard solution was injected into the HPLC system 6 times. A certain average peak area was regressed with a certain level to calculate the calibration equation.

\section{Sample Preparation}

A portion of each homogenized milk or dairy product was weighed $(1 \pm 0.01 \mathrm{~g})$ into a polypropylene centrifuge tube and $5 \mathrm{~mL}$ of acetonitrile:water $(50: 50, \mathrm{vol} / \mathrm{vol})$ was added. The tube was mixed for $1 \mathrm{~min}$, sonicated for 30 min in an ultrasonic cleaning bath, and mixed again on a Vortex mixer for $1 \mathrm{~min}$. The homogenate was centrifuged at 13,200 $\times g$ for 5 min at room temperature, and the supernatant was filtered through a $0.45-\mu \mathrm{m}$ syringe filter into a $2-\mathrm{mL}$ autosampler vial. Then, $250 \mu \mathrm{L}$ of 


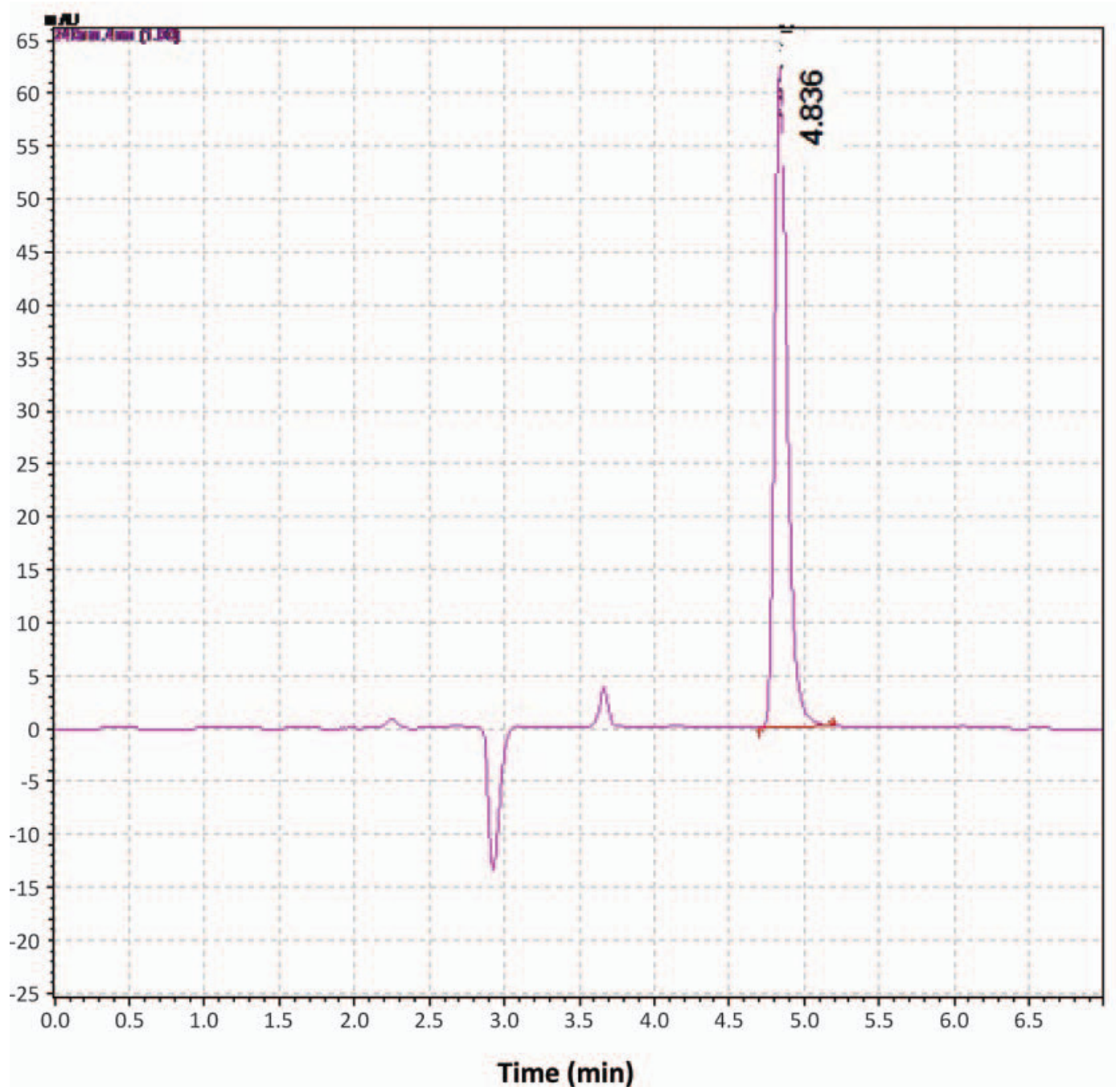

Figure 2. Chromatogram obtained by injecting $20 \mu \mathrm{L}$ of $5 \mu \mathrm{g} / \mathrm{mL}$ melamine standard solution. Color version available in the online PDF.

this filtrate was added to $750 \mu \mathrm{L}$ of water and injected into the HPLC system (Shimadzu, 2008).

\section{Sample Preparation for Method Validation}

A 6-point calibration curve was used to establish instrument response. Quantities of 0.05, 0.1, 0.5, 1, 2.5, and $5 \mu \mathrm{g}$ of melamine were added to $1 \mathrm{~g}$ of milk or dairy product, and standard addition samples were treated as described above under Sample Preparation. For the assessment of precision and accuracy, 4 spiking levels were added to $1 \mathrm{~g}$ of sample (6 replicates were done for each level) as listed in Table 2. Fortified samples were treated as described above under Sample Preparation. The recoveries of melamine from milk and dairy products at each concentration were calculated by means of standard calibration curves with the peak area. The limit of detection (LOD) for this method was defined as the concentration at which the signal-to-noise ratio (measured from the injection of standard solutions containing melamine) was $3: 1$. The limit of quantification (LOQ) was defined as the lowest concentration of analytes that could be determined with acceptable precision and accuracy.

\section{Samples}

In total, 300 domestic and imported dairy products (UHT milk, pasteurized milk, fruit yogurt, milk powder, powdered infant formula, and soft cheese, 50 samples of each) were purchased from national chain grocery stores in Ankara, Turkey, between June 1 and June 30, 2010. All of the milk, yogurt, and cheese samples were domestic products, but $84 \%$ of milk powders (42 samples) and $78 \%$ of infant formulas (39 samples) were imported. Samples were obtained via convenience sampling, where every unique item containing milk as a major ingredient was purchased for analysis. 
Table 3. Selective methods for the quantification of melamine in milk and dairy products ${ }^{1}$

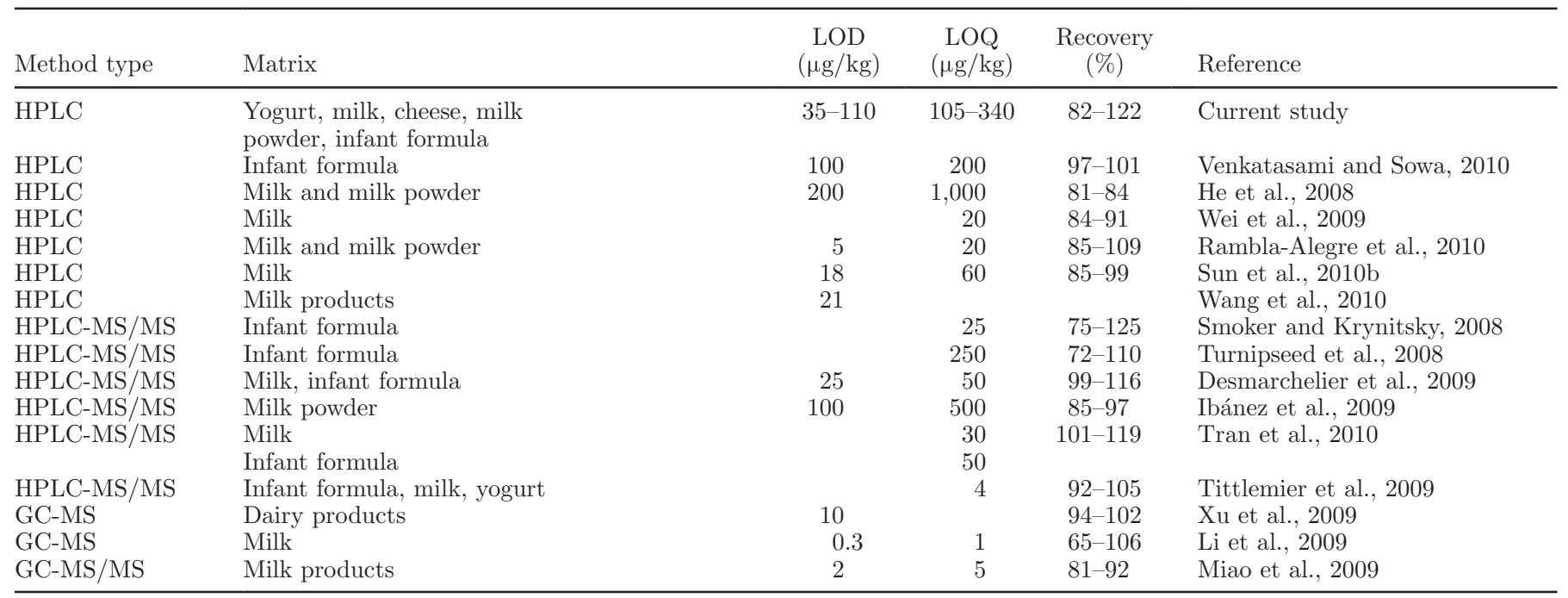

${ }^{1} \mathrm{LOD}=$ limit of detection; $\mathrm{LOQ}=$ limit of quantification.

\section{RESULTS AND DISCUSSION}

\section{Method Performance}

Several dairy products, in either liquid or solid form, were used to develop the method. They were fortified with melamine and then tested under the same conditions to reveal matrix effects and possible interferences.

Melamine is a weakly alkaline compound that can hydrolyze in strong acid or alkali solutions. Melamine extraction can be carried out under neutral, acidic, or alkali conditions, but acidic $(\mathrm{pH} \leq 3)$ and neutral extraction conditions are most common for food. Neutral extraction can be carried out using acetonitrile:water or methanol:water mixtures (Sun et al., 2010a). In this study, an acetonitrile:water mixture was used.

Sample purification is of major importance in various analytical fields. Dairy products contain many proteins and fats that can interfere with melamine analysis, so suitable and effective purification procedures are nec-

Table 4. Range of melamine levels detected in milk and dairy products sold in some markets

\begin{tabular}{lccc}
\hline Dairy product & $\begin{array}{c}\text { Positive } \\
\text { products (no.) }\end{array}$ & $\begin{array}{c}\text { Contamination } \\
\text { range (mg/kg) } \\
\text { (geometric mean) }\end{array}$ & Reference \\
\hline UHT milk & 0 & - & $\begin{array}{c}\text { Current study } \\
\text { Current study } \\
\text { Pasteurized milk }\end{array}$ Current study $^{\text {Current study }}$ \\
Powdered infant formula & 0 & - & Current study \\
Cheese & 1 & 0.121 & Current study \\
Milk powder & 4 & $0.505-0.86(0.694)$ & Chen and Yan, 2009 \\
Yogurt & 22 & $0.136-0.479(0.294)$ & Chen and Yan, 2009 \\
Liquid milk & 1 & 22.8 & Xu et al., 2009 \\
Powdered infant milk & 3 & $1.32-23.63(8.5)$ & Gossner et al., 2009 \\
Ice cream, liquid milk and milk powder & 61 & $0.01-6,175$ & Gossner et al., 2009 \\
Powdered infant formula & 22 & $0.1-2,563$ & Gossner et al., 2009 \\
Liquid milk and yogurt & 52 & $0.6-648$ & Gossner et al., 2009 \\
Powdered milk products & 56 & $<1-6,196$ & Sun et al., 2010b \\
Frozen dairy products & 6 & $4.4-60.8$ & Sun et al., 2010b \\
Raw liquid milk & 2 & $2.09-2.19(2.14)$ & Sun et al., 2010b \\
Semi-finished liquid milk & 3 & $1.67-1.89(1.81)$ & Tittlemier et al., 2009 \\
Flavored liquid milk & 5 & $0.08-1.74(0.36)$ & Tittlemier et al., 2010 \\
Infant formula & 71 & $0.0431-0.346(0.016)$ & Tittlemier et al., 2010 \\
Cheese, soft & 0 & & Tittlemier et al., 2010 \\
Milk & 1 & 0.00742 & Tittlemier et al., 2010 \\
Milk, condensed and evaporated & 4 & $0.0175-0.0307(0.0254)$ & Tittlemier et al., 2010 \\
Milk powder & 2 & $0.00528-0.0122(0.00802)$ & Schoder, 2010 \\
Yogurt & 0 & $0.5-5.5$ &
\end{tabular}

${ }^{1} \mathrm{mg} / \mathrm{L}$ for liquid milk. 
essary before instrument analysis (Sun et al., 2010a). For this reason, disposable syringe filters were used in this study. This hydrophilic membrane removes watersoluble oligomers and polymers such as proteins, with a binding capacity for proteins of $82 \mu \mathrm{g}$ per $25-\mathrm{mm}$ filter.

Reversed-phase liquid chromatography is an excellent separation technique for ionizable molecules. Because melamine is a basic analyte $\left(\mathrm{p} K_{\mathrm{a}}=5.0\right)$ under acidic conditions, the analyte is fully protonated in the mobile phase and the residual silanol groups on the silica support of the column packing are also protonated (Venkatasami and Sowa, 2010). In the present work, a Nucleosil C8 column was used for the separation of melamine in milk and dairy products. The mechanism of separation was ion-pairing with sodium octane sulfonate. Because the particle size of column was small $(3 \mu \mathrm{m})$, the flow rate was adjusted to 1.0 $\mathrm{mL} / \mathrm{min}$ to compensate for the higher back pressure. The calibration curves (Figure 1) indicated no interference from milk and dairy products, and the melamine signal was clearly distinguished at 4.836 min (Figure 2). In addition, samples spiked with 0.05 to $5 \mathrm{mg} / \mathrm{kg}$ of melamine showed recoveries ranging from 95 to $109 \%$, with relative standard deviation values ranging from 0.8 to $2 \%$, indicating that the method was accurate over the tested concentration range (Table 2).

The LOD, LOQ, and recovery of this method for the determination of melamine in some dairy products were compared with other reported methods (Table 3). A sensitive and validated HPLC method for the determination of melamine residue in milk and dairy products was developed. The proposed method was sensitive, reliable, and accurate, and permitted the detection of melamine residues at levels as low as 105 to $340 \mu \mathrm{g} /$ $\mathrm{kg}$ in different dairy products. The method can be used for the routine determination of melamine residues in different dairy products.

\section{Presence of Melamine in Milk and Dairy Products Sold in Turkey}

Melamine was not found in infant formulas and pasteurized or UHT milk samples, whereas $2 \%$ of cheese samples (1 sample), $8 \%$ of milk powder samples (4 samples), and $44 \%$ of yogurt samples (22 samples) contained melamine at $121,694 \pm 146$ (range 505-860), and $294 \pm 98$ (range 136-479) $\mu \mathrm{g} / \mathrm{kg}$ levels, respectively, and compared with the melamine levels detected in milk and dairy products sold in some markets (Table 4). These findings were below the limits set by Codex Alimentarius Commission (2010) and EU legislation (European Commission, 2002, 2009; $1 \mathrm{mg} / \mathrm{kg}$ for infant formula, $2.5 \mathrm{mg} / \mathrm{kg}$ for dairy products). We assumed that the lower amounts detected were the result of con- tamination during the preparation of dairy products and the higher amounts the result of deliberate addition. The consumption of foods containing these low levels of melamine does not constitute a health risk for consumers.

\section{CONCLUSIONS}

A simple, precise, reliable, accurate, and validated reversed-phase HPLC method was developed for the determination of melamine in UHT and pasteurized milk and powdered infant formula, fruit yogurt, soft cheese, and milk powder. The LOD and LOQ of the method were sufficient to detect melamine in milk and dairy products under the safety limits recommended by the Codex Alimentarius Commission. The proposed method can be used for the routine determination of melamine residues in milk and dairy products.

\section{ACKNOWLEDGMENTS}

This study was supported by Ankara University (BAP Project No: 10B3338002).

\section{REFERENCES}

Chen, Z., and X. Yan. 2009. Simultaneous determination of melamine and 5-hydroxymethylfurfural in milk by capillary electrophoresis with diode array detection. J. Agric. Food Chem. 57:8742-8747.

Codex Alimentarius Commission. 2010. Codex Alimentarius Commission (CAC) Codex general standard for contaminants and toxins in food and feed (Codex Standard 193-1995). Accessed May 7, 2011. http://www.codexalimentarius.net/download/standards/17/CXS_193e.pdf.

Desmarchelier, A., M. G. Cuadra, T. Delatour, and P. Mottier. 2009. Simultaneous quantitative determination of melamine and cyanuric acid in cow's milk and milk-based infant formula by liquid chromatography-electrospray ionization tandem mass spectrometry. J. Agric. Food Chem. 57:7186-7193.

Ehling, S., S. Tefera, and I. P. Ho. 2007. High-performance liquid chromatographic method for the simultaneous detection of the adulteration of cereal flours with melamine and related triazine by-products ammeline, ammelide, and cyanuric acid. Food Addit. Contam. 24:1319-1325.

European Commission. 2002. Commission Directive 2002/72/EC of 6 August 2002 relating to plastic materials and articles intended to come into contact with foodstuffs. Off. J. L220:18.

European Commission. 2009. Commission Regulation 1135/2009/EC of 25 November 2009 imposing special conditions governing the import of certain products originating in or consigned from China, and repealing Commission Decision 2008/798/EC. Off. J. L311:3.

Gossner, C. M. E., J. Schlundt, P. B. Embarek, S. Hird, D. Lo-FoWong, J. J. O. Beltran, K. N. Teoh, and A. Tritscher. 2009. The melamine incident: Implications for international food and feed safety. Environ. Health Perspect. 117:1803-1808.

Guo, Z., P. Gai, T. Hao, S. Wang, D. Wei, and N. Gan. 2011. Determination of melamine in dairy products by an electrochemiluminescent method combined with solid-phase extraction. Talanta 83:1736-1741.

He, Q., M. Liu, L. Huang, Y. Yang, and S. Liao. 2008. Determination of melamine in milk powder and milk by high performance liquid chromatography. Se $\mathrm{Pu}$ 26:752-754.

Ibánez, M., J. V. Sancho, and F. Hernández. 2009. Determination of melamine in milk-based products and other food and beverage 
products by ion-pair liquid chromatography-tandem mass spectrometry. Anal. Chim. Acta 649:91-97.

Li, J., H. Y. Qi, and Y. P. Shi. 2009. Determination of melamine residues in milk products by zirconia hollow fiber sorptive microextraction and gas chromatography-mass spectrometry. J. Chromatogr. A 1216:5467-5471.

Miao, H., S. Fan, Y. N. Wu, L. Zhang, P. P. Zhou, J. G. Li, H. J. Chen, and Y. F. Zhao. 2009. Simultaneous determination of melamine, ammelide, ammeline, and cyanuric acid in milk and milk products by gas chromatography-tandem mass spectrometry. Biomed. Environ. Sci. 22:87-94.

Rambla-Alegre, M., J. Peris-Vicente, S. Marco-Peiro, B. Beltran-Martinavarro, and J. Esteve-Romero. 2010. Development of an analytical methodology to quantify melamine in milk using micellar liquid chromatography and validation according to EU regulation 2002/657/EC. Talanta 81:894-900.

Schoder, D. 2010. Melamine milk powder and infant formula sold in East Africa. J. Food Prot. 73:1709-1714

Shimadzu. 2008. Examples of the analysis of melamine in foodstuffs. Accessed April 1, 2008. http://www.shimadzu-france.com/enews/ decembre/files/Shimadzu_Melamine.pdf.

Smoker, M. S., and A. J. Krynitsky. 2008. Interim Method for Determination of Melamine and Cyanuric Acid Residues In Foods using LC-MS/MS: Version 1.0. Laboratory Information Bulletin No. 4422. Center for Food Safety and Applied Nutrition, United States FDA, Washington, DC.

Sun, F., W. Ma, L. Xu, Y. Zhu, L. Liu, C. Peng, L. Wang, H. Kuang, and C. Xu. 2010a. Analytical methods and recent developments in the detection of melamine. Trends Analyt. Chem. 29:1239-1249.

Sun, H., L. Wang, L. Ai, S. Liang, and H. Wu. 2010b. A sensitive and validated method for determination of melamine residue in liquid milk by reversed phase high-performance liquid chromatography with solid-phase extraction. Food Contr. 21:686-691.

Tittlemier, S. A. 2010. Methods for the analysis of melamine and related compounds in foods: A review. Food Addit. Contam. $27: 129-145$.

Tittlemier, S. A., B. P. Y. Lau, C. Menard, C. Corrigan, M. Sparling, D. Gaertner, X. L. Cao, and B. Dabeka. 2010. Baseline levels of melamine in food items sold in Canada. I. Dairy products and soy-based dairy replacement products. Food Addit. Contam. B $3: 135-139$.
Tittlemier, S. A., B. P. Y. Lau, C. Menard, C. Corrigan, M. Sparling, D. Gaertner, K. Pepper, and M. Feeley. 2009. Melamine in infant formula sold in Canada: Occurrence and risk assessment. J. Agric. Food Chem. 57:5340-5344.

Tran, B. N., R. Okoniewski, R. Storm, R. Jansing, and K. M. Aldous. 2010. Use of methanol for the efficient extraction and analysis of melamine and cyanuric acid residues in dairy products and pet foods. J. Agric. Food Chem. 58:101-107.

Turnipseed, S. B., C. Casey, C. Nochetto, and D. N. Heler. 2008 Determination of melamine and cyanuric acid residues in infant formula using LC-MS/MS. Laboratory Information Bulletin No. 4421. Center for Food Safety and Applied Nutrition, United States FDA, Washington, DC.

Tyan, Y. C., M. H. Yang, S. B. Jong, C. K. Wang, and J. Shiea. 2009 Melamine contamination. Anal. Bioanal. Chem. 395:729-735.

Venkatasami, G., and J. R. Sowa. 2010. A rapid, acetonitrile-free, HPLC method for determination of melamine in infant formula. Anal. Chim. Acta 665:227-230.

Wang, G. Y., J. Chen, and Y. P. Shi. 2010. Hollow-fiber liquid-phase microextraction combined with high-performance liquid chromatography for analysis of melamine in milk products. Acta Chromatogr. 22:307-321.

Wei, R., R. Wang, Q. Zeng, M. Chen, and T. Liu. 2009. High-performance liquid chromatographic method for the determination of cyromazine and melamine residues in milk and pork. J. Chromatogr. Sci. 47:581-584.

WHO (World Health Organization). 2009. Toxicological and health aspects of melamine and cyanuric acid. Accessed October 1, 2011. http://whqlibdoc.who.int/publications/2009/9789241597951_eng. pdf.

Wu, Q. Q., K. X. Fan, W. Sha, H. Q. Ruan, R. Zeng, and C. H. Shieh 2009. Highly sensitive detection of melamine based on reversed phase liquid chromatography mass spectrometry. Chin. Sci. Bull. 54:732-737.

Xu, X. M., Y. P. Ren, Y. Zhu, Z. X. Cai, J. I. Han, B. F. Huang, and Y. Zhu. 2009. Direct determination of melamine in dairy products by gas chromatography/mass spectrometry with coupled column separation. Anal. Chim. Acta 650:39-43. 